\title{
Automotive Seating Foams with Excellent Riding Comfort Prepared by a Novel Polypropylene Glycol
}

\author{
By Hiroshi WADA, ${ }^{*}$ Yoshinori TOYOTA, Akio HORIE, Takayuki SASAKI, \\ Chitoshi SUZUKI, and Hiroki FUKUDA
}

\begin{abstract}
A novel polypropylene glycol (designated PPG) which contains an extremely smaller amount of by-products (monols) was developed to improve the riding comfort of an automotive seating foams. The current trend in the automotive seating industry is moving to low resilience molded foam due to the structure change from "full foam" to "foam and high tension spring combination," new automotive seating foams were desired to have low resilience with keeping the low transmissibility at $6 \mathrm{~Hz}$. Riding comfort mainly consists of three factors such as static property, dynamic property and durability. Each issue was solved by means of increasing the polymer molecular weight and the crosslinking density in the polymer matrix. Furthermore, it was also cleared that the transmissibility at resonance frequency of the foam can lower by means of the adjustment of closed cell ratio in the foam. In this paper, we describe the foam properties (static property, dynamic property, durability) of TDI/MDI based molded foams and make clear the mechanism of the Riding comfort of automotive seating foams.
\end{abstract}

KEY WORDS: Flexible Polyurethane Foam / Polypropylene Glycol / Riding Comfort / Static Property / Dynamic Property /

Since the early 1960's flexible molded polyurethane foams have been used for automotive seat cushions, and riding comfort of them has been also studied. Riding comfort of the automotive seat cushion consists of three major factors. One is static property regarding the support for passenger and the others are dynamic property to isolate the vehicle body vibration due to roughness of road surface, and durability of foams. The static property has been evaluated by forcedeflection behavior. Comfort or lack of it defined by means of measuring the hysteresis, sag factor, breathability and resilience of a seating foam. On the other hand, The dynamic property of the foam is generally estimated through a factor of vibration characteristics such as resonance frequency and vibration transmissibility. A human body responds to or oscillates at different frequency at each body part. As it is impossible for the automotive seat cushion to absorb all vibration, it is effective to absorb the vibrations of the region of 4-8 HZ, especially a vibration near $6.0 \mathrm{~Hz}$ which considered to be most undesirable for passengers. ${ }^{1}$ Usually, the improvement of vibration characteristics for the automotive seat cushion has been studied by the control of thickness, hardness and air flow of the seating foam. However, these studies have not been satisfied with the requirements for the automotive seat cushion. ${ }^{2}$ A general method to reach that target has been to provide foams with higher resilience in order to lower the resonance frequency and to reduce the transmissibility at $6 \mathrm{~Hz} .^{3}$ But this method results in increasing transmissibility at a resonance frequency, and is inconsistent with the required property for seating foams which are to absorb or cut off all vibrations at a frequency of $1-20 \mathrm{~Hz}$. The current trend in the automotive seating industry is moving to low resilience molded foam due to the structure change from "full foam" to "foam and high tension spring combination." new automotive seating foams are desired to have low resilience with keeping the low transmissibility at $6 \mathrm{~Hz}$ because of the improvement of riding comfort. In this paper, we report the performance of a newly developed automotive seating foams using a novel polypropylene glycol(designated PPG).

\section{EXPERIMENTAL}

\section{PPG}

Table I shows the chemical structure of each PPG. All PPG were produced by Asahi Glass Urethane Co., Ltd. Hydroxyl number (designated OHV) and unsaturation value (designated USV) were measured according to JIS 1557, and actual functionality (designated F) was calculated by eq 1, where Fn is functionality of initiator of PPG.

$$
\mathrm{F}=(\mathrm{OHV} / 56.1) /\{[(\mathrm{OHV} / 56.1)-\mathrm{USV}][(1 / \mathrm{Fn})+\mathrm{USV}]\}(1)
$$

Table I. Properties of each PPG

\begin{tabular}{cccc}
\hline PPG & PPG-A & PPG-B & PPG-C \\
\hline $\begin{array}{c}\text { Hydroxly NO. } \\
\text { (mg-KOH/g) }\end{array}$ & 24.0 & 23.9 & 24.2 \\
Molecular Weight & 7013 & 7042 & 6955 \\
Capped EO content (\%) & 17 & 17 & 14 \\
Viscosity & 1600 & 1700 & 1300 \\
(mPa-s) & & & \\
Unsaturation value & 0.017 & 0.030 & 0.096 \\
$\begin{array}{c}\text { (m-eq/g) } \\
\text { Functionality of initiater }\end{array}$ & 3.00 & 3.00 & 3.00 \\
Actual functionality & 2.78 & 2.63 & 2.08 \\
\hline
\end{tabular}


Table II. Foaming formulation

\begin{tabular}{lc}
\hline \multicolumn{1}{c}{ Raw Materials } & pbw \\
\hline PPG $^{1}$ & 60 \\
Polymer Polyol $^{2}$ & 40 \\
Crosslinker $^{3}$ & 3.0 \\
Diethanol amine & 1.0 \\
Water & 3.0 \\
Amine Catalyst & 0.6 \\
Silicone Surfactant & 1.0 \\
Isocyanate & INDEX (MDI/TDI =80/20) \\
\hline
\end{tabular}

1: PPG-A, PPG-B, PPG-C

2: $\mathrm{OHV}=23 \mathrm{mg}-\mathrm{KOH} / \mathrm{g}$, Viscosity $=4500 \mathrm{mPa} \cdot \mathrm{s}\left(25^{\circ} \mathrm{C}\right)$ Type of dis-

persed Polymer $=$ Acrylonitril/Styrene Copolymer

3: $\mathrm{OHV}=445 \mathrm{mg}-\mathrm{KOH} / \mathrm{g}$, Viscosity $=4500 \mathrm{mPa} \cdot \mathrm{s}\left(25^{\circ} \mathrm{C}\right)$

4: C-1021 produced by Nippon Polyurethane Industry Co., Ltd. $\mathrm{NCO}=44.8 \%$

The molecular weight of each polyol was determined by $\mathrm{OHV}$. PPG-A was synthesized by double metal cyanide(designated DMC) catalyst. ${ }^{4}$ PPG-B and PPG-C were synthesized by cesium hydroxide(designated $\mathrm{CsOH}$ ) catalyst $^{5}$ and potassium hydroxide (designated $\mathrm{KOH}$ )catalyst, respectively And each PPG was ethylene oxide (designated EO) capped to adjust the reactivity to isocyanate. PPG-A and PPG-B contain an extremely smaller amount of by-products (monools).

\section{Foaming Procedure}

Test foams were prepared using a general hand mixing procedure. An steel mold with dimensions of $400 \times 400 \times$ $100 \mathrm{~mm}$ was used and the mold temperature was kept at $60 \pm 1{ }^{\circ} \mathrm{C}$. The raw material's temperature (polyol side/ isocyanate side) was controlled at $25 \pm 1{ }^{\circ} \mathrm{C}$. The overall density of the foams was set at $50 \mathrm{~kg} / \mathrm{m}^{3}$. The formulation for this study was shown in Table II. The isocyanate was a mixture of TDI and polymeric MDI at a ratio of $80 / 20$.

\section{Physical Properties of Foams}

Physical properties of foams were measured according to JIS K6400, airflow were measured according to ASTM D-1564 to determine the open cell ratio in molded foams. Foam hardness was represented as 25\%-ILD and resilience of foams were also provided as ball rebound.

\section{Static Property}

Hysteresis and sag factor were measured according to automotive standard JASO B408-89. ${ }^{6}$ The sag factor is simply the ratio of the force required to compress a specimen to $65 \%$ and $25 \%$ deflection. The initial low $25 \%$ ILD gives a luxurious feel while the correspondingly higher ILD at $65 \%$ deflection provides necessary firmness for support. Hysteresis is a measurement of energy loss or absorbed by foams when subjected to a deformation.

\section{Dynamic Property}

Vibration characteristics for each of the foam were measured according to JASO B408-89 test methods using a $50 \mathrm{~kg}$ load and an input amplitude of 5 millimeters.
Table III. Physical Properties of each Foam

\begin{tabular}{lccc}
\hline \multicolumn{1}{c}{ Foam } & Foam-A & Foam-B & Foam-C \\
\hline Overall Density $\left(\mathrm{kg} / \mathrm{m}^{3}\right)$ & 48.1 & 49.2 & 49.6 \\
Core Density $\left(\mathrm{kg} / \mathrm{m}^{3}\right)$ & 43.6 & 44.7 & 44.8 \\
25\%-ILD $\left(\mathrm{N} / 314 \mathrm{~cm}^{2}\right)$ & 224 & 202 & 185 \\
Airflow (L/min) & 38 & 77 & 84 \\
Elongation $(\%)$ & 88 & 78 & 81 \\
Tensile Strength $(\mathrm{kPa})$ & 150 & 123 & 120 \\
Tear Strength $(\mathrm{N} / \mathrm{cm})$ & 6.1 & 5.2 & 5.0 \\
Ball Rebound $(\%)$ & 68 & 71 & 69 \\
\hline
\end{tabular}

\section{Durability}

Dynamic fatigue test was measured according to JASO B408-89 which is the measurement of the hardness loss after compression for 80,000 cycles.

\section{RESULTS AND DISCUSSION}

\section{Physical Properties}

Table III shows the physical properties of each foam. Lower monool content in PPG provides a positive effect on tensile strength, tear strength and hardness of foams. These improvements are assumed by increasing of the polymer molecular weight. The relationship between functionality and theoretical polymer molecular weight calculated by Carothers equation was reported in the previous report. ${ }^{7}$

A foam using PPG-A (designated Foam-A) shows superior physical properties because of the above mentioned theory.

\section{Riding Comfort of Automotive Seating Foams}

Riding comfort of an automotive seating foam has been studied by means of static property, dynamic property and durability. The recent trend in the automotive seat cushion is to move to the low resilience molded foam with better physical properties. The influence of the monool content in PPG for riding comfort was discussed in the following section.

\section{Static Property}

Table IV shows the static property of each foam. High sag number has been generally thought to indicate an extra comfort seating. The initial low 25\%ILD give a luxurious feel while the correspondingly higher ILD at $65 \%$ deflection provides necessary firmness for support. However, it has been also reported that the foams having sag factors of about 2.8 or greater are generally credited having an extra comfort rating. ${ }^{8}$

Ball Rebound test used to measure the surface resilience of flexible polyurethane foam. Recently, a high resilience automotive seating foams with ball rebound of $70 \%$ or higher have

Table IV. Static Properties of each Foam

\begin{tabular}{lccc}
\hline \multicolumn{1}{c}{ Foam } & Foam-A & Foam-B & Foam-C \\
\hline Sag Factor & 2.84 & 3.02 & 3.11 \\
Hysteresis (\%) & 20 & 21 & 21 \\
Ball Rebound (\%) & 68 & 71 & 69 \\
\hline
\end{tabular}


been required for improvement of dynamic property. ${ }^{3}$ However, in case of the static property, Hartings and Hargen ${ }^{9}$ have shown that ball-rebound test was correlatable to comfort as rated by a panel of judge. According to the average opinion of the panel of judge, $40 \%$ rebound was considered to be the critical value for initial comfort. The static property of Foam-A is acceptable for the requirements of the seating foams because of the above mentioned theory, however, the behavior of its static property is different from the other foams using PPG-B and PPG-C (designated Foam-B and Foam-C, respectively). this phenomenon can be explained the following theory. Foam-A contains some closed cells with small rupture holes, the passage of air in and out of the cells was observed from the airflow data in Table III. Generally, it has been thought that this type of an automotive seating foam has a undesirable comfort because of the increase of the hysterisis, ${ }^{10}$ however, the hysteresis of each foam showed similar numbers. These results suggest that a drastic reduction of the monool in PPG can make up for the lack of the elasticity of polymer in Foam-A despite including the closed cell in Foam-A.

\section{Dynamic Property}

Recently, Griffin et al. have been investigated to improve the riding comfort by appropriate modeling of the seat passenger system. ${ }^{11-13}$ However, It has been well known that the vibration damping characteristics of automotive seating foams are represented by the spring and dash-pot model illustrated in Figure $1,{ }^{14}$ this model remains useful for understanding the performance mechanism of automotive seating foams. ${ }^{1}$ There has been generally a demand to automotive seating foams of lower transmissibility at resonance frequency and at $6 \mathrm{~Hz}$ to prevent the transmission of vibration for human body, and mechanism of riding comfort has been studied by means of the dynamic mechanical behavior of open-cell flexible foams containing compressible and incompressible fluids. ${ }^{15-17}$

Table $\mathrm{V}$ shows the vibration characteristic of each foam. The foam's viscoelastic response may be modeled as the combination of a spring with spring constant (designated $\mathrm{K}$ ) in

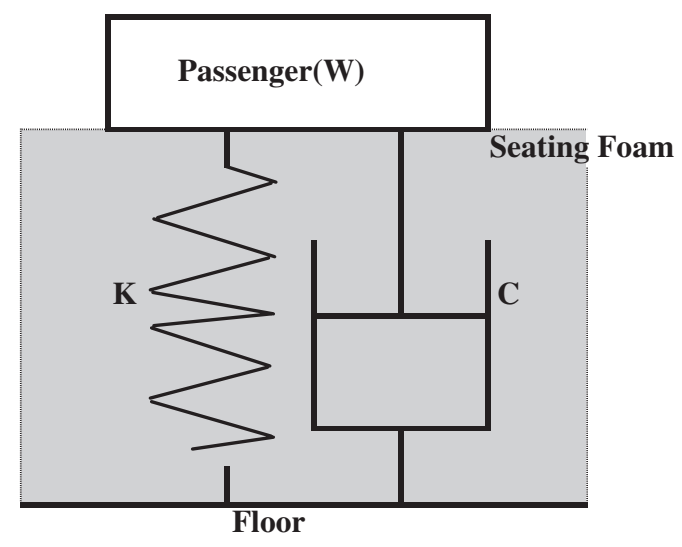

Figure 1. Spring and dash-pot model.
Table V. Vibration Characteristics of each Foam

\begin{tabular}{lccc}
\hline \multicolumn{1}{c}{ Foam } & Foam-A & Foam-B & Foam-C \\
\hline $\begin{array}{l}\text { Resonance Frequency } \\
\text { (HZ) }\end{array}$ & 3.45 & 3.48 & 3.64 \\
$\begin{array}{l}\text { Transmissibility at } \\
\text { Resonance Frequency }\end{array}$ & 4.5 & 5.4 & 5.3 \\
Transmissibility at $6 \mathrm{HZ}$ & 0.65 & 0.70 & 0.80 \\
\hline
\end{tabular}

Table VI. Dynamic Spring Constant K and Damping Factor C of each Foam

\begin{tabular}{lccc}
\hline \multicolumn{1}{c}{ Foam } & Foam-A & Foam-B & Foam-C \\
\hline $\begin{array}{l}\text { Dynamic Spring Constant K } \\
\left(\mathrm{Nm}^{-1}\right)\end{array}$ & $2.35 \times 10^{4}$ & $2.39 \times 10^{4}$ & $2.62 \times 10^{4}$ \\
$\begin{array}{l}\text { Damping Factor C } \\
\left(\mathrm{Nsm}^{-1}\right)\end{array}$ & $2.43 \times 10^{2}$ & $2.04 \times 10^{2}$ & $2.16 \times 10^{2}$ \\
\hline
\end{tabular}

$\mathrm{Nm}^{-1}$ and a dashpot of damping factor (designated $\mathrm{C}$ ) in $\mathrm{Nsm}^{-1} \cdot 1,6$ The resonance frequency (designated $\mathrm{Fr}$ ) in $\mathrm{Hz}$ and the transmissibility at the peak resonance frequency (designated Ar) can be represented by the following equations.

$$
\begin{aligned}
& \mathrm{Fr}=1 / 2 \pi(\mathrm{Kg} / \mathrm{W})^{1 / 2} \\
& \mathrm{Ar}=1 / \mathrm{C}(\mathrm{KW} / \mathrm{g})^{1 / 2}
\end{aligned}
$$

where $\mathrm{g}$ being the gravity constant in $\mathrm{ms}^{-2}$ and $\mathrm{W}$ being the applied load in N. K and C of each foam were calculated by the use of the eqs 2 and $3 . \mathrm{K}$ and $\mathrm{C}$ of each foam were obtained by substituting the experimental data in Table $\mathrm{V}$ for eqs 2 and 3.

Calculated results show Table VI. K of Foam-A was lower than that of Foam-B and Foam-C. On the other hand, the damping factor $\mathrm{C}$ of Foam-A was higher than that of Foam-B. These results suggest that the improvement of the dynamic property of foams is possible to be carried out the decrease of $\mathrm{K}$ and the increase of $\mathrm{C}$ of each foam simultaneously.

The decrease of $\mathrm{K}$ is accomplished by means of decreasing the amount of monools in PPG, namely, as it has been already discussed in physical properties section, the increase of the polymer molecular weight can provide the outstanding elasticity for the polymer matrix. On the other hands, The cell in foam is composed between resin rib and skin, onset of cell opening occurs several seconds after the onset of urea phase separation, ${ }^{18}$ and airflow is finally ensured to tear the skin in the cell by crushing process. Therefore, it is usually difficult to adjust a degree of closed cell ratio. However, Foam-A includes partially closed cell after crushing process, therefore it shows high $\mathrm{C}$ number compared with the other foams. This reason can be explained the following observation. It is assumed that the urea hard domains of the foam using PPG synthesized by DMC catalyst are small $(<0.2 \mu \mathrm{m})$ and disperse uniformly in the rib, ${ }^{19}$ accordingly, open cell mechanism by urea domains can not fulfill their function.

\section{Durability}

We have selected the durability performance test (hardness loss after 80,000 cycles test) according to the JASO B 408-89 method in order to evaluate durability. Table VII shows the 
Table VII. Durability1 of each Foam

\begin{tabular}{cccc}
\hline Foam & Foam-A & Foam-B & Foam-C \\
\hline CLD Loss (\%) & 13.8 & 14.2 & 14.6 \\
\hline
\end{tabular}

results of this test. These data indicate that Foam-B improves the durability performance in comparison with the Foam-C, and moreover Foam-A was more effective than Foam-B to improve the durability.

The above mentioned results show that the improvement of durability is provided by the increase of the polymer molecular weight and the crosslinking density in the polymer matrix in the foam.

\section{CONCLUSION}

Riding comfort which consist of static property, dynamic property and durability of the foams was improved by reduction of by-products(monools) in PPG. The novel PPG which contains an extremely smaller amount of monool has solved each requirement of automotive seating foams, it makes the increase of the polymer molecular weight and the crosslinking density in the polymer matrix possible. Furthermore, transmissibility at resonance frequency of the foam could be kept lower by means of the adjustment of closed cell ratio in the foam

\section{REFERENCES}

1. F. M. Casati, R. M. Herrington, R. Broos, and Y. Miyazaki, J. Cell. Plastic., 34, 430 (1998).

2. T. Sato, F. Nakamura, and O. Kondo, presented at Proceedings of the Fourth International Pacific Conference on Automotive Engineering, 299, Melbourne, 1987.

3. K. W. Suh, C. P. Park, M. J. Maurer, M. H. Tusim, R. D. Genova, R. Broos, and D. P. Sophiea, Adv. Mater., 12, 23 (2000).

4. M. Ionescu, "Chemistry and Technology of Polyols for Polyurethanes," Rapra Technology Limited., United Kingdam, 2005, pp 167-183.

5. M. Ionescu, "Chemistry and Technology of Polyols for Polyurethanes," Rapra Technology Limited., United Kingdam, 2005, pp 167-183.

6. Japanese Automobile Standard Organization, B 408-89, (1989).

7. S. D. Seneker, N. Barksby, and B. D. Lawrey, presented at Proceedings of the Polyurethanes Expo'96, Las Vegas, 1996.

8. N. C. Hilyard, "Mechanics of Cellular Plastics," Applied Science Publishers Ltd., Chapter 3, England, 1982, p. 105.

9. N. C. Hilyard, "Mechanics of Cellular Plastics," Applied Science Publishers Ltd., Chapter 3, England, 1982, p. 103.

10. N. C. Hilyard, "Mechanics of Cellular Plastics," Applied Science Publishers Ltd., Chapter 3, England, 1982, p. 102.

11. T. E. Fairly and M. J. Griffin, J. Biomechanics, 22, 81 (1998).

12. L. Wei and M. J. Griffin, J. Sound. Vib., 212, 855 (1998).

13. L. Wei and M. J. Griffin, J. Sound. Vib., 214, 121 (1998).

14. J. H. Varterasian, SAE Paper, NO. 770249, 1977, p. 1-10.

15. A. N. Gent and K. C. Rusch, Rubber Chem. Technol., 39, 389 (1966).

16. R. E. Blake, "Shock and Vibration Handbook," 2nd ed., C. M. Harris and C. E. Crede, Ed., McGraw-Hill, 1961, Chap. 41.

17. N. C. Hilyard, J. Sound. Vib., 32, 71 (1974).

18. K. Yasunaga, R. Neff, and C. W. Macosko, J. Cell. Plastic., 32, 427 (1996).

19. Y. Toyota, N. Hasegawa, H. Wada, A. Horie, S. Hatano, T. Sasaki, and S. Oki, presented at Proceedings of the Polyurethanes World Congress, Amsterdam, 1997. 